\title{
Productivity Enhancement Using Kinetic Modeling of Bio-digestion Process-A Review
}

\author{
Manish Baweja ${ }^{1}$, Prashant Baredar ${ }^{2}$, Rajiv R. Lal ${ }^{1}$ \\ ${ }^{1}$ Department of Mechanical Engineering, AISECT University, Bhopal, India \\ ${ }^{2}$ Department of Energy, Maulana Azad National Institute of Technology, Bhopal, India
}

Email address:

Manishbaweja2001@rediffmail.com (M. Baweja)

\section{To cite this article:}

Manish Baweja, Prashant Baredar, Rajiv R. Lal. Productivity Enhancement Using Kinetic Modeling of Bio-digestion Process-A Review. American Journal of Energy Engineering. Vol. 5, No. 4, 2017, pp. 17-25. doi: 10.11648/j.ajee.20170504.11

Received: June 8, 2017; Accepted: July 12, 2017; Published: September 5, 2017

\begin{abstract}
Bio-digesters convert organic waste (agricultural and food waste, animal or human manure, and other organic waste), into energy (in the form of biogas or electricity). An added benefit to bio-digestion is a leftover high-grade organic fertilizer. Models of the Bio digestion process do exist, but either relies on simple algebraic equations instead of biochemical reactions, or considers so many external parameters that they become overly complicated and require much input information and computation time. This work provides the review of features and limitations of different kinetic models of bio digestion process to enhancement on productivity.
\end{abstract}

Keywords: Bio-digestion, Kinetic Model, Organic Material, Fertilizer, pH

\section{Introduction}

Bio digesters convert organic waste (agricultural and waste, animal or human manure, and different organic waste), into energy (in the shape of biogas or electricity). The advantages that the bio digestion method provides are waste management, energy production, and plant food production.

Waste management is extremely necessary in each urban and rural setting. Most industrial elements of the planet have already got waste management systems, although they typically may be improved with regards to environmental impact. Rural areas typically lack sanitation or reliable waste management systems, and this can be an extremely valuable service for health and environmental reasons.

Bio digestion will offer energy to those that don't have already had it, or will manufacture clean energy as another to carbon-intensive energy production. Energy provided to those that don't have already had it allows societies to accomplish additional, and permits for a way higher quality of life. Clean energy is gaining additional importance as world energy consumption grows and humans have additional of a bearing on the world climate.
The fertilizer by-product is another profit which will add price to a bio digestion system. Once a feedstock is consumed by the Bio digestion method, the leftover material may be used as a soil additive to reinforce crop production. In rural settings, this fertilizer is best used regionally or onsite of the Bio autoclave.

Biogas created from Bio digestion typically has high amounts of sulfur that is what causes associate uncomfortable smell. This is often solely terribly problematic if the intent is to use the biogas during a cell, as a result of the sulfur can poison the cell. There are sulfur scrubbers offered to get rid of the sulfur if the intent is to use the biogas during a cell, however this adds considerably to value. If the gas is simply to be burned as change of state fuel or during a generator, then sulfur production isn't essentially a drag.

\subsection{Biochemical Process of Bio-digestion}

Bio digestion is a process of degradation of a substance in the absence of oxygen. The process occurs in the stomachs of animals, and the same biological process found in nature can be replicated and controlled by engineers. There are four major steps of Bio digestion, shown in figure 1. 


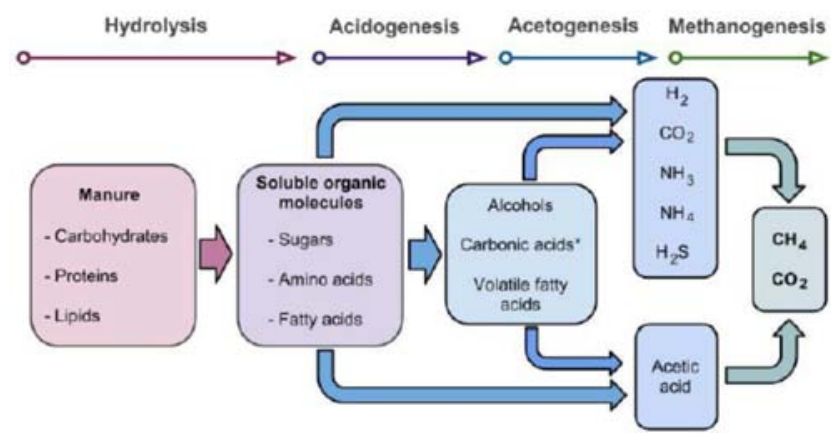

Figure 1. Biochemical process of bio-digestion.

The first step within the Bio digestion method, reaction is that the cleavage of chemical bonds by the addition of water. The sterilizer feedstock could also be created up of many various elements and materials, and so there are many various versions of hydrolysis; carbohydrates, fats, and proteins are all broken down into smaller molecules by this first step of Bio digestion. Acidogenic bacterium degrades the product of chemical reaction into volatile fatty acids. Some hydrogen, carbon dioxide, and carboxylic acid also are created, which can skip the acetogenesis stage. Within the third step of Bio digestion, acetogenic bacteria consume precursors and manufacture acetate (acetic acid). The ultimate step of Bio digestion is that the formation of alkane by bacteria known as methanogens. For the most half, the organic process here is that the breakdown of acetic acid although different types of the reaction can even turn out methane via Bio digestion.

\subsection{Other Parameters That Influence Gas Production}

Gas production from a Bio digester depends on the ability of bacteria to thrive inside the digester. The survival of bacteria depends on the temperature, $\mathrm{pH}$, and physical conditions of the Bio digester.

\subsubsection{Temperature \& Pressure}

Temperature for fermentation will greatly affect biogas production. Depending on prevailing conditions methane can be produced within a fairly wide range of temperature. The process of anaerobic fermentation and methane forming bacteria works best in the temperature between $29^{\circ} \mathrm{C}$ to $41^{\circ} \mathrm{C}$ or between $49^{\circ} \mathrm{C}$ to $60^{\circ} \mathrm{C}$ and pressure of about 1.1 to 1.2 bars absolute. This is due to fact that two different types of bacteria multiply best in these two different ranges, but the high temperature bacteria are much more sensitive to ambient influences. The rate of gas production increases with the increase in temperature but the percentage of methane reduces. It is found that temperature between $32^{\circ} \mathrm{C}-35^{\circ} \mathrm{C}$ are most efficient for stable and continuous production of methane. Biogas produced outside this range will have a higher percentage of carbon dioxide and other gases than within this range. The production of biogas is fastest during summer and it decreases at lower temperature during winter. If the temperature are lower than $20^{\circ} \mathrm{C}$ the rate of gas production falls sharply and it almost ceases at about $10^{\circ} \mathrm{C}$. Also methanogemic microorganisms are very sensitive to temperature changes, a sudden change exceeding $30^{\circ} \mathrm{C}$ will affect production, and therefore one must ensure relative stability of temperature. Thus, in cold climates, it is necessary to heat the digester to about $35^{\circ} \mathrm{C}$.

There are three Bio digestion operational temperature ranges. Psychrophilic digestion occurs at below $25^{\circ} \mathrm{C}$, or below room temperature. Mesophilic digestion occurs between 25 and $45^{\circ} \mathrm{C}$, while thermophilic digestion occurs above $45^{\circ} \mathrm{C}$. In general, higher temperatures result in higher biogas production. Further, rapid temperature changes can upset bacterial activity, so for experimental studies, it is important that temperature is held constant.

\subsection{2. $\mathrm{pH}$}

$\mathrm{pH}$ value indicates the degree of acidity or alkalinity of a solution. The $\mathrm{pH}$ value is represented as the logarithm of the reciprocal of the hydrogen ion concentration in gm equivalent per litre of solution. $\mathrm{pH}$ value in the range $0-7$ represents acidic solution and in the range 7-14 indicates the alkaline solution. The micro-organisms require a neutral or mildly alkaline environment - a too acidic or too alkaline environment will be detrimental. Ideal $\mathrm{pH}$ value is between 7.0-8.0 but can go up or down by a further 0.5 . In the initial stages of acid forming stage of digestion, the $\mathrm{pH}$ value may be around 6.0 or less, however during methane formation stage the $\mathrm{pH}$ value higher than 7.0 is maintained since methane formers are sensitive to acidity. The $\mathrm{pH}$ value depends on the ratio of acidity and alkalinity and the carbon dioxide content in the digester, the determining factor being the density of the acids. For the normal process of fermentation, the concentration of volatile acid measured by acetic acid should be below 2000 parts per million too high a concentration will greatly inhibit the action of the methanogenic microorganisms.

The survival of methanogenic bacteria also depends on the acidity of the environment that they are in: methanogenesis requires a near-neutral $\mathrm{pH}$ (between 6.5 and 7.5). A decrease in $\mathrm{pH}$ can inhibit gas production and can lead to further accumulation of acids.

\subsubsection{Nutrients Concentration}

The major nutrients required by the bacteria in the digester are $\mathrm{N}_{2}, \mathrm{P}, \mathrm{S}, \mathrm{C}, \mathrm{H}_{2}$, and $\mathrm{O}_{2}$ to accelerate the anaerobic digestion rate. Thus it is necessary that the major nutrients are supplied in correct chemical form and concentrations. The carbon in carbohydrates supplies the energy and the nitrogen in proteins is needed for building of growth of bacteria. The bacteria responsible for the anaerobic process require both elements nitrogen and carbon, as do all living organisms, but they consume carbon roughly 30 times faster than nitrogen. Assuming all other conditions are favourable for biogas production, a carbon-nitrogen ratio of about $30: 1$ is ideal for the raw materials fed into a biogas plant with $2 \%$ phosphorous for maximum biological activity. A higher ratio will leave carbon still available after the nitrogen has been 
consumed, starving some of the bacteria of this element. These will in turn die, returning nitrogen to the mixture, but slowing the process. Too much nitrogen will cause this to be left over at the end of digestion (which stops when the carbon has been consumed) and reduce the quality of the fertilizer produced by the biogas plant. The correct ratio of carbon to nitrogen will prevent loss of either fertilizer quality or methane content. Thus, for acceleration fermentation and production of biogas nutrients like $\mathrm{C}, \mathrm{P}$ and $\mathrm{N}_{2}$ are maintaining within the optimum range. Oil cakes and animal urine are found to be suitable nutrients for this purpose.

\subsubsection{Solid Concentration and Loading Rate}

The cow dung, water and various organic residues from agricultural waste are supplied as feed to the digester. The proportions recommended are: Cow dung + solid waste 1:1 by weight and forming to about $10 \%$ of solid content and $90 \%$ of water. The amount of feed supply per day to the digester is called loading rate. It is dependent on the size of the plant.

The recommended loading rate is about $0.2 \mathrm{~kg} / \mathrm{m}^{3}$ of digester capacity. The under loading and overloading reduces the biogas production. The loading of feed must be carried out every day at the same time as to keep the solid concentration ratio constant in the digester.

\subsubsection{Retention Period}

It represents the time period for which the fermentable material remains inside the digester. This period ranges from 35 days to 50 days depending upon the climatic conditions and location of the digester. The longer retention period needs larger size digester and it allows more complete digestion of feed.

\subsubsection{Water Content}

This should be about $90 \%$ of the weight of the total contents. With too much water the rate of production per unit volume in the pit will fall, preventing optimum use of the digester. If the water content is too low, acetic acid will accumulate, inhibiting the fermentation process and hence production and also thick scum will be formed on the surface. The water content differs according to the raw material used for fermentation. Nature of organic materials, materials rich in cellulose and semi-cellulose with sufficient protenaceous substance produce more gas. Complex polysaccharides are more favorable for methane formation while only protenacous materials produce little quantity of gas.

\subsubsection{Reaction Period}

Under optimum condition $80-90 \%$ of total gas production is obtained within a period of 3-4 weeks.

Size of the fermentation tank also decides the reaction period. It is found that the biogas production per unit volume of digester is high when its diameter to depth ratio ranges between 0.66 to 1 .

\subsubsection{Mixing and Other Physical Conditions}

Contact between bacteria and the slurry that they are consuming is vital to the Bio digestion process. One way to maximize this contact is to keep the digester thoroughly mixed at all times.

Methanogens naturally live inside the stomachs of animals, and attach to the stomach lining as a way to secure a safe habitat with a steady supply of food. When placed inside of a man-made Bio digester, instead of floating around in the slurry, the bacteria attach to surfaces while being exposed to the flow of digestible material. Some Bio digester designs address this issue by creating internal structures so that bacteria can attach to them and be exposed to more digestible material. Otherwise, mixing is an important design parameter in maximizing Bio digestion performance because it allows enhanced contact between bacteria and the material being consumed. In case of cow dung, as it contains all the nutrients needed by organisms for the production of methane there is no necessity for addition of nutrients to it.

\subsection{History and Use of Bio Digestion}

The generation of combustible gas from decomposing organic matter has been known for decades. In 1776, Volta determined that the amount of organic material and the amount of gas produced were directly connected. John Dalton and Humphrey Davy established that the combustible gas was methane in 1804-1808. Bio digestion was applied to a septic tank in 1881 , and has since been applied to wastewater treatment at much larger scales. In developing countries, where energy production is generally scarcer and more expensive, Bio digestion may have more relevance in the absence of strong alternatives. Notably, India is credited for having built the first-ever Bio digester in 1897, using human waste to meet lighting needs. Intensive plant design and technology research began in the 1950s, and the application of Bio digestion has grown over time. The largest biogas program in the world is in India, where over 20 percent of rural households use biogas.

\subsection{Application of Bio-digestion System}

Bio digesters are very useful in agricultural settings, given that they take inputs of agricultural products and produce energy and fertilizer which can both be used at these sites. They are also useful in industrial settings, where economies of scale can be realized by handling large throughputs of material. They can be designed to take in virtually any type of organic waste, including plant matter, animal excrement, and by-products of industrial processes. Bio digesters range in size from as small as taking in the food scraps from one family to as large as entire wastewater treatment plants for a large city. 


\section{Review of Literature}

Table 1. Review of Literature.

\begin{tabular}{l}
\hline Author/ Year/ Ref. \\
\hline \\
Anthony Njuguna \\
Matheri, Mohamed \\
Belaid and Tumisang \\
Seodigeng, Jane \\
Catherine Ngila et al. \\
[1]
\end{tabular}

Iqbal Syaichurrozi et al. [2]

Ilona Sárvári

Horváth, Meisam

Tabatabaei,

Keikhosro Karimi

and Rajeev Kumar et

al. [3]

Anthony Njuguna

Matheri, Mohamed

Belaid and Tumisang

Seodigeng, Jane

Catherine Ngila et al.

[4]

Anthony Njuguna

Matheri, Mohammed

Belaid, Tumisang

Seodigeng, and

Catherine Jane Ngila et al. [5]

Elena Cristina Rada,

Marco Ragazzi,

Paolo Stefani, Marco

Schiavon and

Vincenzo Torretta et al. [6]
Objective

The Role of Trace Elements on Anaerobic Co-digestion in Biogas Production

Review - Biogas Technology to Treat Bioethanol Vinasse

Recent updates on biogas production - a review

Modelling the Kinetic of Biogas Production from Codigestion of Pig Waste and Grass Clippings

The Kinetic of Biogas Rate from Cow Dung and Grass Clippings

Modelling the Potential Biogas Productivity Range from a MSW Landfill for Its Sustainable Exploitation

\section{Conclusion}

Investigated were within permissible limits suitable for biogas production. In general, codigestion of organic substrate improves the abundance of trace elements thus increasing the concentration of micro and macro nutrients. The main inference from the above discussion is that traces elements maybe inhibitory, stimulatory and even toxic to anaerobic digestion, where the extent depends on elements concentration. The concentration of trace metals in the digester should be monitored under retention time to guarantee the efficiency of methane formation. Further comprehensive research to determine the optimum concentration for micro and macro nutrients and their interaction with microbial activity in anaerobic digestion is required. Review indicates that vinasse must be treated first before discharged in to the environment. Vinasse has negative impact to environment because of its contents such as COD, TS, nitrogen, color, etc. High temperature and very acidic of $\mathrm{pH}$ in vinasse is also not eco-friendly for environment. Biogas technology is the best choice to treat vinasse. COD content in vinasse will be converted into biogas. Some authors have studied the vinasse treatment through biogas technology. It is more effective to degrade organic materials than aerobic treatment. However, the value of COD removal is not maximum. That is caused by presence of phenolic compounds in vinasse.

Investigated increasing demand for renewable energy compels the exploration of new substrates and the development of new technologies for biogas production. Regarding raw materials for $\mathrm{AD}$, it is preferable to utilize waste streams since in this way, the process addresses both waste reduction and energy production. Lignocellulosic residues are readily available; however, further developments of novel pretreatment technologies are needed to achieve economically viable processes. Anaerobic degradation of organic material requires a well functioning microbial consortium, and methanogenic microorganisms, responsible for methane production within the final step of the digestion process, are known to be the most sensitive ones to process disturbances. This together with their slow growing rate made it necessary to develop novel process configurations aiming at preventing their wash out from the system. In this sense, the development of UASB reactor was an important milestone. In UASB system the formation of a dense well-settle able granular sludge makes an efficient decoupling of SRT and HRT possible.

Conclude Biogas production from co-digestion of pig waste and grass clippings was established to be feasible at a temperature of $37^{\circ} \mathrm{C}$. The application of modified Gompertz equation in studying the biogas production was able to predict biogas production with retention time.

Investigated Biogas production from co-digestion of cow dung and grass clippings was established to be feasible at temperature of $37^{\circ} \mathrm{C}$. The application of modified Gompertz equation in studying the biogas production was able to predict biogas production with retention time.

Investigated absence of knowledge on the hydrological balance of lowland and, consequently, on the water content of the waste entails the inclusion of uncertainties and approximations within the estimation of the biogas potential. The applying of the planned model allowed the generation of a variety of biogas potential curves to account for the variability of the expected biogas flows. The projected model considers the temperature field that's usually established at intervals every layer of waste which controls, in its turn, the anaerobic biodegradation method, for an additional realistic simulation of the biogas production. The estimation of the potential biogas is especially necessary to assess the practicableness of its exploitation for energy functions. The situations created for the simulations dissent one from the opposite for the kinetic constants adopted that are related to the water content of the waste. Of course, the calculated supreme hourly biogas flows on yearly average, on the idea of the situations thought-about, showed an oversized variability, starting from $114 \mathrm{Nm}^{3} \mathrm{~h}^{-1}$ to $180 \mathrm{Nm}^{3} \mathrm{~h}^{-1}$. The results were compared with the output of the Land GEM model (version three.02), a widespread model adopted within the U.S.A. as reference for estimating the gas productivity from landfills. The applying of Land GEM showed the tendency to underestimate the results of the model of Manna changed by the DICAM. To simulate the biogas exploitation by a generator, a group of potency coefficients for the biogas aggregation system was introduced, presumptuous a temporal variability until the year of theoretic disposal of the generator (2026). The variability of the calculated biogas flows showed repercussions for the supreme collectable volume throughout the operational amount. Hence, the provision of knowledge regarding the water content of the lowland is of primary importance, since it's an oversized influence on the dynamics of biodegradation of the organic matter within the waste and on a resulting correct estimation of the biogas productivity, that is key for a analytic thinking if biogas utilization for energy functions is taken into thought. 


\begin{tabular}{ll}
\hline Author/ Year/ Ref. & Objective \\
\hline & \\
& \\
& Modelling the Kinetics of \\
& Biogas Generation from \\
& Mesophilic Anaerobic Co- \\
G. K. Latinwo and S. & $\begin{array}{l}\text { Digestion of Sewage Sludge } \\
\text { with Municipal Organic } \\
\text { E. Agarry et al. [7] }\end{array}$ \\
& Waste
\end{tabular}

\section{Conclusion}

Concluded from the anaerobic digestion of sewage sludge and municipal organic waste as cosubstrate that the addition of co-substrate has the potential of increasing biogas yield and have a positive influence on early biogas production. $\mathrm{pH}$ range of 6.27 to 7.85 and mesophilic temperature range of 26.5 to $31.5^{\circ} \mathrm{C}$ resulted in higher biogas production for both digesters. The maximum cumulative biogas yield was $660 \mathrm{dm} 3$ for digester D1 (100\% sewage sludge) and $1532.2 \mathrm{dm}^{3}$ for digester D2 (50\% sewage sludge $+50 \%$ municipal organic waste), respectively. Exponential plot simulated biogas production rate better than that of linear plot. Modified Gompertz plot and Logistic growth plot both had higher correlation than exponential rise to maximum plot for simulating cumulative biogas production. Therefore, arising from the increasing environmental concern and prevailing wastes management crises; optimizing biogas production by co-digestion of industrial sewage sludge and municipal wastes represents a viable and sustainable energy option.

Improved ignocellulose reaction was achieved by bioaugmenting biogas batch reactors treating BSG with P. xylanivorans Mz5T, C. cellulovorans and F. succinogenes S85, which promoted

Maša Čater, Lijana Fanedl, Špela

Malovrh and Romana Marinšek Logar et al. [8]

Veronika Dollhofer, Sabine Marie Podmirseg, Tony Martin Callaghan, Gareth Wyn Griffith and Kateřina Fliegerová et al. [9]

\section{S. J. Grimberg, D.} Hilderbrandt, $\mathrm{M}$. Kinnunen and S. Rogers et al. [10]

Giovanni Esposito, Luigi Frunzo, Antonio Panico and Francesco Pirozzi et al. [11]

My Carlsson, Anders Lagerkvist and Fernando MorganSagastume et al. [12]
Biogas Production from Brewery Spent Grain Enhanced by Bioaugmentation with Hydrolytic Anaerobic Bacteria

Anaerobic Fungi and Their Potential for Biogas

Production

Anaerobic digestion of food waste through the operation of a mesophilic two-phase pilot scale digester Assessment of variable loadings on system performance

Enhanced bio-methane production from co-digestion of different organic wastes

The effects of substrate pretreatment on anaerobic digestion systems: A review
Gergely Forgács et al. [13]
Biogas Production from Citrus Wastes and Chicken Feather: Pretreatment and Co-digestion", Phd Thesis, biogas production and considerably elevated gas production. The persistence of the foremost productive P. xylanivorans Mz5T in bioreactor isn't stable however seems to be long enough to boost the anaerobic digestion potency. Bioaugmentations caused bigger changes in microorganism than in archaeal community structure, though the addition of $\mathrm{C}$. cellulovorans affected archaea considerably, too. Bioaugmentation could be a promising technique for increasing gas production from BSG and it should broaden the usage of lignocellulose in biogas trade.

Researched in biogas science is to seek out an economical tool to compass the bottleneck possessed by reaction of lignocellulose-rich residues. Besides many physical, mechanical chemical or microbic pretreatment techniques, the employment of anaerobic lignocellulolytic fungi should be useful and even a lot of efficient. The stomach of herbivores may be seen as natural resources for potent biomass degraders. Particularly anaerobic fungi, famous to act as primary digesters, may be sensible candidates. They manufacture a superior set of hemi/cellulolytic enzymes that they eliminate severally or combined in cellulosomes. To boot they're ready to attack the material automatically by their strand growth and open up the tissue for additional digestion by bacteria.

Demonstrated that waste matter on a university field may be dependably biodegraded using a two-stage anaerobic digester system. Once comparison single and two-staged operation, each processes created similar quality effluent. However, the biogas yield was higher for the two-stage system. Despite the potential difficulties with operational the additional complicated system, the two-stage method might be with success maintained through low-loading periods as are generally experienced during summer months on a university field.

Described during this paper demonstrate the benefits for the anaerobic digestion method ensuing from compounding completely different organic wastes. The primary profit is expounded to the chance to create the digestion method quicker, manufacturing a big quantity of alkane even in digesters with a coffee hydraulic retention time (HRT). The second profit is expounded to the chance to decrease the danger of failures for the process once the autoclave is fed with an extremely degradable organic substrate, like OFMSW. Mixing OFMSW with a lower degradable however ammonia-rich substrate, like placental mammal manure, suggests that the system is protected against a pointy call ph, that is the main reason for the digestion method failure. Finally, once the characteristics of the pure substrates are known, the projected mathematical model evaluates a priori that substrates and their percentages should be mixed to optimize the performance of the method. Therefore, this mathematical model may be reasonably applied for the codigestion systems design.

Studied for pre-treatment are WWTP residues with the preponderantly applied ways being thermal and unbearable pre-treatments. Within the cases of the less often studied substrates, chemical and thermal pre-treatments are the ways preponderantly applied to energy crops/harvesting residues, organic waste from food trade and manure, whereas mechanical and thermal pretreatments are principally applied to OFMSW.

Overall, pre-treatments tend to reinforce the biodegradability of most substrates; but, some pretreatments have facet effects that counteract their positive effects, as for instance, WO which will cause the mineralization of organic matter or high-temperature thermal pre-treatments which will cause the generation of recalcitrant compounds. The pre-treatment effects are tangled with substrate characteristics and pretreatment mechanisms. during this sense, some substrates inherently extremely perishable (e.g., primary sludge in WWTP residues) might not want pretreatment, whereas different substrates, like those containing lignin or bacterial cells, are additional correctable to pre-treatment for enhancing AD. Overall, matching pre-treatment techniques to substrate characteristics and kinds remains a challenge.

Focused on biogas production as a waste management tool for two byproducts from the foodprocessing industries, namely citrus wastes from the juice- processing industry and feather waste from poultry slaughterhouses. These waste streams hold a high biogas potential, but are recalcitrant to the anaerobic digestion process in different ways. CWs contain an inhibitory agent, 


\begin{tabular}{ll}
\hline Author/ Year/ Ref. & Objective \\
\hline & $\begin{array}{l}\text { Department of Chemical and } \\
\text { Biological Engineering }\end{array}$ \\
& \\
$\begin{array}{l}\text { Jon K. Pittman, } \\
\text { Andrew P. Dean and } \\
\begin{array}{l}\text { Olumayowa } \\
\text { Osundeko et al. [14] }\end{array}\end{array}$ & $\begin{array}{l}\text { The potential of sustainable } \\
\text { algal biofuel production } \\
\text { using wastewater resources }\end{array}$
\end{tabular}

Osundeko et al. [14]

M. O. L. Yusuf, A.

Debora and D. E.

Ogheneruona et al. [15]

Elias Jigar et al. [16]

Tadious Tesfaye

Tefera et al. [17]

\section{Conclusion}

D-limonene, exerting an antimicrobial effect while feather has a complex structure as the main obstacle. Thus, both waste types are resistible to biological degradation, making a pre-processing step necessary in order to render them suitable for biogas production.

Studied supported current technologies protoctist cultivation for biofuel production alone is unlikely to be economically viable or offer a positive energy come back. Dual-use microalgae cultivation for waste material treatment not to mention biofuel generation is thus a beautiful choice in terms of reducing the energy value, GHG emissions, and also the nutrient (fertilizer) and fresh resource prices of biofuel generation from microalgae. The high biomass productivity of wastewater-grown microalgae suggests that this cultivation methodology offers real potential as a viable suggests that for biofuel generation and is probably going to be one in every of several approaches used for the assembly of property and renewable energy.

Studied biogas production from cow dung and horse dung was established here to be feasible at room temperature. Application of the modified Gomperzt equation in studying the biogas production was able to predict the pattern of biogas production with time. It was observed that the maximum biogas production could be obtained from substrate in digester B $(25 \%$ cow dung and $75 \%$ horse dung) which was closely followed by substrate mixture containing ( $100 \%$ horse dung) and lastly by substrate mixture comprising (50\% cow dung and $50 \%$ horse dung).

Ambient temperature kinetic assessment of biogas production from co-digestion of horse and cow dung

Study on Renewable Biogas Energy Production From Cladodes Of Opuntia FicusIndica

Potential for biogas production from slaughter houses residues in Bolivia
Digesters D and E were classified as failed digesters because of their inability to produce any measurable amount of biogas at the end of the digestion period.

Furthermore, these observations were corroborated using a modified first-order equation. This model was able to establish that substrate in digester B have the highest room temperature short term biodegradability. This was followed by substrate in digester A and lastly by substrate in digester $\mathrm{C}$. Also, the observed $\mathrm{k}$ values for the digesters $\mathrm{A}-\mathrm{C}$ indicated that the reaction could have progressed efficiently. In essence, the short term room temperature kinetic of biogas production from cow dung and horse dung can be effectively studied using the modified Gompertz model and also a modified first-order equation as developed here.

Conclude mean minimum and most close temperature throughout the section of experiment were ten.30C and $24.110 \mathrm{C}$ severally. Hence, during this experiment biogas digesters were kept throughout in sand jacket to manage temperature fluctuation. From this experiment the quantity of biogas created altogether the digesters were starting from 6.1761 to 14.1831 . the most biogas was made during a combination of Cladodes to garbage at the quantitative relation of 25:75 that provides 14.1831 in 66 days of retention time. The biogas made from garbage alone was 13.670 $1\left(0.022 \mathrm{~m}^{3} / \mathrm{kg}\right)$. It is additional revealed that those treatments (T1 and T5) that have a C: N quantitative relation inside the vary of 20-30 is found to perform higher in biogas yield and gas production than that aren't. The carbon to elementquantitative relation of T2 and T4 is on the far side the optimum $\mathrm{C}: \mathrm{N}$ price. This shows that Cladodes biomass is extremely organic having fewer elements thus may want feed stocks that are made in element if used as substrate for biogas production. The result additionally shows that the $\mathrm{pH}$ scale of the digesters throughout the retention time was below acidic condition. During this regard the $\mathrm{pH}$ scale of all the digesters of treatments weren't within the vary of best level $6.7-7.4$ appropriate for many methanogenic bacteria to operate for biogas production. Finally, the standard of the biogas either from Cladodes alone or with combination of garbage additionally were on the far side 500th or were inside the vary of quality biogas. Again from the laboratory result, the Volatile solid content of the Cladodes substrate was seventy eight of the TS. This shows that an oversized fraction of the Cladodes is perishable. This means that Cladodes will function a crucial feedstock for biogas production. Biogas and gas production from T1 $(100 \% \mathrm{CD})$, T3 $(50 \% \mathrm{CD}: 50 \% \mathrm{CL})$ and T5 $(75 \% \mathrm{CD}: 25 \% \mathrm{CL})$ weren't statistically important at 0.5 level. Co-digestion of garbage and Cladodes biomass is thus, a technique of addressing the matter of lack of enough feedstock for biogas production. If appropriate materials for co digestion, like manure, aren't available; Cladodes will be digestible alone and may be a smart chance for poor those who haven't stock. Environmental, suspension andforeign currency edges will be obtained from biogas production.

Conclude Biogas production by anaerobic digestion offers so many advantages in utilizing waste to energy. In this study, it is shown that the advantage is not only for energy sectors but also for the safety of the environment. It is very well advised practice in Bolivia to produce biogas from slaughter house residue which is currently discharged to Lake Titicaca. The study has shown that three major problems impede the realization of potential of producing biogas from the slaughter houses. These impeding factors are the cold climate with fluctuating temperature and the digestion of difficult; unsuitable substrate which is animal blood. Moreover, the economical constraint in Bolivia as developing country to use advanced technology to improve the negative effects resulted due to those factors makes the realization more difficult. Consequently, the main focus of this study is to search innovative and affordable solutions to mitigate the impact due to these factors on biogas production from the slaughter house.

This study showed that cold and fluctuating temperature has direct effect on the growth of microorganisms. The bacterial culture needs very optimal condition to grow and replicate. The culture is more over very sensitive to any slight disturbance in any of the parameters they need for growth. In project area La Paz, the temperature reading of the digester showed fluctuation which is severe disaster for the whole process. Even though the direct effect of low temperature 


\begin{tabular}{ll}
\hline Author/ Year/ Ref. & Objective \\
\hline & \\
& \\
& \\
& \\
Yadvika, Santosh, T. & Enhancement of biogas \\
R. Sreekrishnan, & production from solid \\
Sangeeta Kohli and & substrates using different \\
Vineet Rana et al. & techniques-a review \\
[18] &
\end{tabular}

S. Sambo, B. Garba and B. G. Danshehu et al. [19]

Visvanathan and Abeynayaka et al. [20]

Judd et al. [21]

Youngsukkasem et al. [22]

Budiyono et al. [23]

\section{Conclusion}

at first is inhibiting the growth of the microorganisms, it has an indirect effect on disrupting all other parameters necessary for biogas production. It is discussed that factors like $\mathrm{pH}$, substrate concentration, carbon/nitrogen ratio and all the parameters (factors) in chapter 3 has to be in their optimal condition as required by the microorganisms. The effect of the temperature therefore not only affects the growth of the bacteria culture but also all important factors mentioned ultimately making the realization of the biogas production very difficult.

Analysis of literature reveals that there's a powerful chance to boost the biogas production beneath field conditions. Use of sure inorganic, organic additives appears to be promising for enhancing biogas production. Among differing types of biomass (plant and crop residues) used as additives, some are found to boost the gas production manifolds. However -ever their utility is proscribed owing to the seasonal accessibility in several regions. Also, preventive of the reactor within the long-term is another downside discovered beneath field conditions. Sensible facet of exploitation pure microbe culture as additives should be looked into, in sight of sure issues particularly human health and geodynamics. Any techno-economics of exploitation additives on daily must be puzzled out by any in depth experimentation at field level.

Recirculation of effluent suspension on daily and stirring of the digester's contents by exploitation straightforward techniques for enhancing biogas production appears to be quite viable beneath rural conditions.

Keeping varied parameters among the specified vary additionally improves gas production however the sensible problem lies in maintaining and observation these often. It's a vital purpose that wants due thought since a small amendment in $\mathrm{pH}$ scale or temperature might otherwise end in reduction of gas production. Equally formation of volatile fatty acids beyond a selected vary hinders the methane production. Loading rate and solid concentration should be properly balanced and continuously maintained.

As for the mounted film technique, it's sure deserves over the higher than mentioned strategies. Once the fabric to be used as carrier has been put in within the reactor, the reactor are often operated beneath traditional conditions with none daily addition or watching. Completely different materials (stone chips, iron mesh, clay, wood chips, etc.) had been tried for mounted film reactors looking on their native accessibility and mechanical strength in long-term. It'd facilitate to reduce HRT significantly leading to value reduction of biogas plant, while not compromising on amount and quality of biogas.

Effect of some operating parameters on biogas production rate Developments and future potentials of anaerobic membrane bioreactors (AnMBRs)

Principles and applications of membrane bioreactors for water and wastewater treatment

Performance of semicontinuous membrane bioreactor in biogas production from toxic feedstock containing DLimonene. Bioresour

Predicting Kinetic Model of Biogas Production and Biodegradability Organic Materials: Biogas production from Vinasse at Variation of $\mathrm{COD} / \mathrm{N}$
Reported in this paper clearly show that significant benefits will be derived if conditions favoring optimum gas yield are met. Thus, the temperature, retention period, carbon: nitrogen ratio and $\mathrm{pH}$ of the slurry should be set for optimum biogas production.

Studied membrane bioreactors (MBRs), the membrane forms a selective barrier allowing certain components to pass while retaining others, and thereby the biological system can be protected. The application of MBRs provides both increased SRT by avoiding the wash out of the cells and decreasing inhibitor concentrations by the separation of inhibitors.

Submerged system requires less space and energy, since compared with the external loop system, energy input is not required to maintain a continuous flow through the membrane. However, it could be problematic to operate this system at high particulate and/or cell concentrations, due to fouling. Membrane technologies developed and applied in waste water treatment processes can also be used for biogas production processes. Different studies on membrane technologies in biogas systems reported yields comparable with those obtained with high rate systems, i.e., UASB systems.

Encapsulation of methane-producing bacteria was carried out to test the viability of this technique in biogas processes. One-step liquid-droplet-forming method was used to form spherical capsules of alginate. Chitosan or $\mathrm{Ca}^{2+}$ was used as counter-ions together with the addition of carboxymethyl cellulose. Furthermore, a synthetic Durapore ${ }^{\mathbb{R}}$ membrane (hydrophilic polyvinyldifluorid (PVDF)) was also tested by making encapsulating sachets with dimension of $3 \times 3$ or $3 \times 6 \mathrm{~cm}^{2}$ for holding the bacteria. The results indicated that these membranes allowed the penetration of nutrients into the cells while the gas produced could escape out of the capsules by diffusion. Hence, encapsulation can be a promising method, keeping high density of microorganisms in the system. This theory was further investigated by comparing the ability of encapsulated cells with free cells to handle limonene containing synthetic media during AD. Limonene naturally occurs in citrus waste, making the utilization of this waste stream in biogas processes difficult, due to its inhibitory effects on the biogas producing microorganisms. The results showed the protective effect of the PVDF membrane resulting in faster biogas production by the encased bacteria compared to the free cells.

Reported that organic substances such as acetic acid, lactic acid and glycerol are easy to be degraded using anaerobic technology. Hence, biogas from vinasse is generated easily. In other hand, phenolic compounds in vinasse are difficult to be destroyed through anaerobic technology. It has phytotoxic character so microbial growth in digester will be disturbed. 


\section{Conclusion}

The review indicates different techniques of bio digestion system for production of Bio gas. This review shows the different parameters like environmental temperature, moisture, $\mathrm{pH}$ levels, pressure, supplements and dimensions of system and other mixing material, which are affecting the production of bio gas. After studied different review of literature following conclusion are defined:

1. Temperature and pressure of Bio Gas plant plays important role of production. Its optimum level gives high production rate of gas.

2. Other supplements are also increase the production of the Bio Gas, but excess level of supplements is harmful for co generation.

3. Cow waste, Pig Waste, Human Waste, Trees etc. are used in co generation on bio gas plant. After generation of gas, wastage is used in agriculture.

4. Dimension of plant and storage plant is also affecting the production.

5. $\mathrm{pH}$ level is also play a significant role of production of gas generation.

\section{References}

[1] Anthony Njuguna Matheri, Mohamed Belaid and Tumisang Seodigeng, Jane Catherine Ngila, "The Role of Trace Elements on Anaerobic Co-digestion in Biogas Production", Proceedings of the World Congress on Engineering 2016 Vol II WCE 2016, June 29 - July 1, 2016, London, U. K.

[2] Iqbal Syaichurrozi, "Review - Biogas Technology to Treat Bioethanol Vinasse", Waste Technology, Vol. 4(1), 2016, pp 16-23.

[3] Ilona Sárvári Horváth, Meisam Tabatabaei, Keikhosro Karimi and Rajeev Kumar, "Recent updates on biogas production - a review”, Biofuel Research Journal 10, 2016, pp 394-402.

[4] Anthony Njuguna Matheri, Mohamed Belaid and Tumisang Seodigeng, Jane Catherine Ngila, "Modelling the Kinetic of Biogas Production from Co-digestion of Pig Waste and Grass Clippings" Proceedings of the World Congress on Engineering 2016 Vol II WCE 2016, June 29 - July 1, 2016, London, U. K.

[5] Anthony Njuguna Matheri, Mohammed Belaid, Tumisang Seodigeng, and Catherine Jane Ngila, "The Kinetic of Biogas Rate from Cow Dung and Grass Clippings", th International Conference on Latest Trends in Engineering \& Technology (ICLTET'2015) Nov. 26-27, 2015 Irene, Pretoria (South Africa).

[6] Elena Cristina Rada, Marco Ragazzi, Paolo Stefani, Marco Schiavon and Vincenzo Torretta, "Modelling the Potential Biogas Productivity Range from a MSW Landfill for Its Sustainable Exploitation", Sustainability 2015, 7, pp 482-495.

[7] G. K. Latinwo and S. E. Agarry, "Modelling the Kinetics of Biogas Generation from Mesophilic Anaerobic Co-Digestion of Sewage Sludge with Municipal Organic Waste", Chemical and Process Engineering Research, Vol. 31, 2015, pp 43-53.
[8] Maša Čater, Lijana Fanedl, Špela Malovrh and Romana Marinšek Logar, "Biogas Production from Brewery Spent Grain Enhanced by Bioaugmentation with Hydrolytic Anaerobic Bacteria", Bioresource Technology, 5 March 2015, pp 1-35.

[9] Veronika Dollhofer, Sabine Marie Podmirseg, Tony Martin Callaghan, Gareth Wyn Griffith and Kateřina Fliegerová; "Anaerobic Fungi and Their Potential for Biogas Production", Springer International Publishing, Switzerland 2015, pp 41-61.

[10] S. J. Grimberg, D. Hilderbrandt, M. Kinnunen and S. Rogers, "Anaerobic digestion of food waste through the operation of a mesophilic two-phase pilot scale digester - Assessment of variable loadings on system performance", Bioresource Technology 178, 2015, pp 226-229.

[11] Giovanni Esposito, Luigi Frunzo, Antonio Panico and Francesco Pirozzi, "Enhanced bio-methane production from co-digestion of different organic wastes", Environmental Technology, Vol. 33, No. 24, December 2012, pp 2733-2740.

[12] My Carlsson, Anders Lagerkvist and Fernando MorganSagastume, "The effects of substrate pre-treatment on anaerobic digestion systems: A review", Waste Management 32,2012 , pp 1634-1650.

[13] Gergely Forgács, "Biogas Production from Citrus Wastes and Chicken Feather: Pretreatment and Co-digestion", Phd Thesis, Department of Chemical and Biological Engineering, Chalmers University of Technology, Göteborg, Sweden 2012.

[14] Jon K. Pittman, Andrew P. Dean and Olumayowa Osundeko, "The potential of sustainable algal biofuel production using wastewater resources", Bioresource Technology 102, 2011, pp $17-25$.

[15] M. O. L. Yusuf, A. Debora and D. E. Ogheneruona, “Ambient temperature kinetic assessment of biogas production from codigestion of horse and cow dung", Res. Agr. Eng. Vol. 57, 2011, No. 3, pp 97-104.

[16] Elias Jigar. "Study on Renewable Biogas Energy Production From Cladodes Of Opuntia Ficus-Indica", M. Tech Thesis, School of Graduate Study, Addis Ababa University, July, 2010.

[17] Tadious Tesfaye Tefera, "Potential for biogas production from slaughter houses residues in Bolivia", Master of Science Thesis, STOCKHOLM 2009.

[18] Yadvika, Santosh, T. R. Sreekrishnan, Sangeeta Kohli and Vineet Rana, "Enhancement of biogas production from solid substrates using different techniques - a review", Bio resource Technology 95, 2004, pp 1-10.

[19] A. S. Sambo, B. Garba and B. G. Danshehu, "Effect of some operating parameters on biogas production rate", Renewable Energy, Vol. 6, No. 3, pp. 343-344, 1995.

[20] Chettiyappan Visvanathan and Amila Abeynayaka, "Developments and future potentials of anaerobic membrane bioreactors (AnMBRs)", Membrane Water Treatment, Vol. 3, No. 1, 2012, pp 1-23.

[21] Judd, S, "Principles and applications of membrane bioreactors for water and wastewater treatment". MBR Book, Elsevier, Oxford. 2010. 
[22] Wikandari, R., Youngsukkasem, S., Millati, R., Taherzadeh, M. J., "Performance of semi-continuous membrane bioreactor in biogas production from toxic feedstock containing DLimonene. Bioresour". Technol. 170, 2014, pp. 350-355.

[23] Syaichurrozi, I., Budiyono, Sumardiono, S. "Predicting Kinetic Model of Biogas Production and Biodegradability Organic Materials: Biogas production from Vinasse at Variation of COD/N", Bio resource Technology, 149, 2013, pp 390-397.

[24] Pagés-Díaz, J., Westman, J., Taherzadeh, M. J., Pereda-Reyes, I., Sárvári Horváth, I. "Semi-continuous co-digestion of solid cattle slaughterhouse wastes with other waste streams: Interactions within the mixtures and methanogenic community structure". Chem. Eng. J. 273, 2015, pp 28-36.

[25] Yong, Z., Dong, Y., Zhang, X., Tan, T., "Anaerobic codigestion of food waste and straw for biogas production". Renew. Energ. 78, 2015, pp 527-530.
[26] Chasnyk, O., Sołowski, G., Shkarupa, O. "Historical, technical and economic aspects of biogas development: Case of Poland and Ukraine". Renew. Sust. Energy Rev. 52, 2015, pp 227-239.

[27] Pore, S. D., Shetty, D., Arora, P., Maheshwari, S., Dhakephalkar, P. K., "Metagenome changes in the biogas producing community during anaerobic digestion of rice straw". Bioresour. Technol. doi: 10.1016/j.biortech.2016.03.045.

[28] Suksong, W., Kongjan, P., Prasertsan, P., Imai, T., O-Thong, S. "Optimization and microbial community analysis for production of biogas from solid waste residues of palm oil mill industry by solid-state anaerobic digestion". Bioresour. Technol. 214, 2016, pp 166-174. 